brane. The effect of this when the sound-producing motion set in was to cause the membrane to wrinkle sharply towards the point of convergence ; and, by experiment on the dead insect with the point of a pencil, it was easy to see that the sound was simply produced by this sharp wrinkling of the membrane. If a piece of stiff paper or parchment be held in the fingers, and the thumb be made to play sharply and rapidly upon it in succession, so as to produce a "kink" or wrinkle each time, a very fair representation of the sound of the insect will be produced. A captive insect, when the motion is slowing down, can be advantageously watched; it will then be seen that, as the sound divides up into separate clicks, the membrane becomes alternately wrinkled and flat. Beyond doubt the sound is no humming.

North-West Himalaya, March 14

\section{Ferocity of Animals}

I HAVE read with interest the article by Prof. Lloyd Morgan "On the Study of Animal Intelligence" in the present number of Mind, in which he touches upon the subject of entangling fact and inference which attracted my attention when reading "Mental Evolution in Animals" some time since.

I write to call Prof. Morgan's attention to the excellent example of "ejective inference" given by Dr. Romanes in his letter in NATURE for April I (p. 513), where he says of a rat that he "perfectly understood my object." Would it be troubling Dr. Romanes too much to ask him to explain the appearance a wild rat presents on "perfectly well understanding " the object of a human being's actions ?

Churchfield, Edgbaston, April 5

\section{F. H. Collins}

\section{Tropical Dew}

HAVING had occasion to lay out a large quantity of iron boes and picks, without handles, on the hard ground of an open inclosure in one of the driest districts in India (Beliary), where, in fact, these implements had been collected in the face of a scarcity, it was found, after they had lain a couple of months, that a thick, weedy, but luxuriant vegetation had sprung up, enough, though there had been no rain, to almost hide the tools.

The effect depositing tools on grass has had in stimulating its growing the writer has observed in the tropics before, but was at a loss to account for it, except upon some irresolvable theory of radiation or magnetism.

The whole phenomenon is cleared up by Mr. Aitken's paper on "Dew" in NATURE of January r 4 (p.256), dew being proved deposited, not, as generally thought, from the air above, but rising and conden ing from the soil below ; and the ground in India is always hygroscopic. The outer surfaces of the iron tools radiate of course quickly at night, and the stratum of air inclosed between the metal under surfaces and the earth is therefore saturated with condensing moisture.

That iron gratings laid on bare ground will raise a rank vegetation in places with only ro or 15 inches of annual rainfall, and exposed to tropical heat, is a not unimportant fact, as being a readily available substitute for irrigation water, worth further investigation.

India, March 26

A. T. FRASER

\section{The Climbing Powers of the Hedgehog}

I AM advised by some of my friends to send you a notice of the mode in which hedgehogs may frequently escape from confinement, and of their habits.

I obtained a hedgehog last week, and put it in my kitchen. Every day it is placed in a small back area, about i 2 feet square, during the day-time. The waste-pipes from the cisterns discharge into this area, and the animal frequently lies under these, and as my servant says, "wallows in the trough like a pig." If he hears any noise he at once runs to a corner and rolls himself up.

On Wednesday the servant found him on the top of the parti tion wall between my area and the next. This wall is vertical, height 9 feet 6 inches. The top course but one projects $\mathrm{I}$ inch, so he must have climbed over this.

He has been watched in the operation. He climbs by the projecting mortar beds, which are rather rough, looking about him frequently to see if he is watched. He climbs up the house wall beside the pipe in the corner-an ordinary iron rain-pipe; but from the shoulder of the pipe, where it passes through the wall, to the top of the partition wall, there is a distance of 9 inches without any pipe, so up this portion and over the projecting brick course he must have climbed by clinging to the wall of the house or the partition wall.

Yesterday (Thursday) he repeated the ascent, and descended into the next area, where he was found this morning.

6, Elm Park Gardens, April 16

KOBERT H. SCOTT

\section{STARS WITH BANDED SPECTRA}

$\mathrm{THE}$ spectroscopic survey of the northern heavens, undertaken conjointly by MM. Vogel and Dunér in I 879 , has already progressed so far that its general results can be fairly anticipated-its immediate results, that is to say; for it is ultimately designed, not so much for a collection of statistics, however valuable and interesting, as for a criterion of change. This effect, however, must wait for the future-perhaps a remote future-to develop; we can in the meantime gather much present knowledge through labours inspired by still unfolded possibilities.

The first instalment of the first spectroscopic starcatalogue systematically executed, was published by Vogel in 1883 (Publicationen des astrophysikalischen Observatoriums zu Potsdam, No. I I). It covers a zone of the heavens extending from $-2^{\circ}$ to $+20^{\circ}$ of declination, and includes $405 \mathrm{I}$ stars down to $7^{\circ} 5$ magnitude. $\mathrm{M}$. Dunér now sends us from Lund, in a catalogue of 352 stars fully ascertained to possess spectra of the fluted and zoned types, a work of special and extreme importance.

Stars with banded spectra fall into two perfectly distinct classes, of which the first is well exemplified in a Orionis (Betelgeux), the second in a 5.5 magnitude star close behind the Great Bear, numbered I 52 in Schjellerup's Catalogue of Red Stars (Astr. Nach., No. I 591), and called by Father Secchi "La Superba," from the extraordinary vivacity of its prismatic rays. The spectrum of Betelgeux (Fig. I) shows a series of seven or eight wellmarked dark bands (besides minor shadings) all abruptly terminated towards the violet, and dying out by insensible gradations towards the red. The impression upon the eye resembles that of a colonnade thrown into strong relief by a vivid side-illumination. Only three conspicuous dark spaces, on the other hand, interrupt the beams of 152 Schjellerup (Fig. 3); but their breadth is fully twice that of the flutings in the spectrum of $\alpha$ Orionis; and, still more remarkable, they face in the opposite direction. Their obscurity deepens slowly downwards towards their less refrangible sides, then suddenly, by a sharp transition, and with a singular and splendid effect of contrast, gives place to unclouded light.

The stars characterised by these two different qualities of absorption, respectively constituted Father Secchi's third and fourth spectral orders. M. Vogel, however, saw fit in 1874 (Astr. Nach., No. 2000) to modify the arrangement by grouping the two varieties together as subdivisions of a single class. Nor was this a mere arbitrary change. It was the outcome of a far-reaching speculation regarding the course of development taken by the great army of suns marshalled in the profundities of space.

Secchi's classification involved no hypothesis of any kind; it was founded simply on appearances. But the iclea that the colours, consequently the spectra of stars, may guide us to a knowledge of their comparative "ages," thrown out in a crude shape by Zöllner in 1865 , had, meantime, made its way. Vogel's adoption of it as a means of rationalising observed particulars, gave it (perhaps prematurely) a recognised scientific status.

According to this view, the white stars forming Secchi's first order (of which Sirius and Vega may be taken as

I "Sur les Étoiles à Spectres de la Troisième Classe." Par N. C. Dunér. Mémoire présenté à l'Académie Royale des Sciences de Suède, le ir Juin, 1884. (Stockholm, r884.) 